
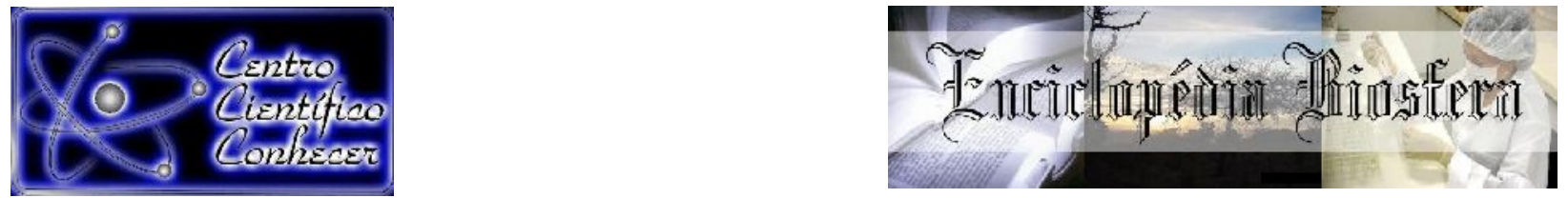

\title{
ESCARIFICAÇÃO MECÂNICA COM LIXA EM SEMENTES DE Senna macranthera (Dc. Ex Collad.) H.S. Irwin \& Barneby
}
Evandro Luiz Missio ${ }^{1}$, Cleber Witt Saldanha ${ }^{2}$, Joseila Maldaner ${ }^{3}$, Gerusa Pauli Kist Steffen $^{4}$, Rosana Matos de Morais ${ }^{5}$
${ }^{1}$ Centro de Pesquisa em Florestas (DDPA/SEAPDR), Santa Maria, Rio Grande do Sul-evandro.missio@gmail.com
${ }^{2}$ Pesquisador Doutor - Centro de Pesquisa em Florestas (DDPA/SEAPDR), Santa Maria, Rio Grande do Sul.
${ }^{3}$ Pesquisadora Doutora - Centro de Pesquisa em Florestas (DDPA/SEAPDR), Santa Maria, Rio Grande do Sul.
${ }^{4}$ Pesquisadora Doutora - Centro de Pesquisa em Florestas (DDPA/SEAPDR),
Santa Maria, Rio Grande do Sul.
${ }^{5}$ Pesquisadora Doutora - Centro de Pesquisa em Florestas (DDPA/SEAPDR), Santa Maria, Rio Grande do Sul.

Recebido em: 15/11/2020 - Aprovado em: 15/12/2020 - Publicado em: 30/12/2020 DOI: 10.18677/EnciBio_2020D46

\section{RESUMO}

Senna macranthera é uma espécie florestal nativa do Brasil de grande ocorrência natural. Sua propagação ocorre por sementes, as quais apresentam dormência tegumentar e necessitam de tratamento para a multiplicação. O objetivo deste trabalho foi avaliar o efeito da escarificação mecânica com lixa em sementes de $S$. macranthera. Foram testados quatro tempos de escarificação mecânica $(0,1,2$ e 4 segundos) e dois tipos de embebição (sem embebição e com embebição por 24 horas), em delineamento inteiramente casualizado, com quatro repetições. O tempo de escarificacão de 1 segundo, sem embebição, apresentou os melhores resultados para as variáveis de vigor e germinação das sementes. Os resultados mostraram que: a escarificação mecânica de sementes de $S$. macranthera com lixa 80 em cilindro rotativo por 1 segundo, sem embebição, é recomendada para a superação da dormência tegumentar; a embebição de sementes de S. macranthera por 24 horas não contribui para a superação da dormência tegumentar.

PALAVRAS-CHAVE: dormência de sementes, cilindro rotativo, germinação.

\section{MECHANICAL SCARIFICATION WITH SANDPAPER IN SEEDS OF Senna macranthera (Dc. Ex Collad.) H.S. Irwin \& Barneby}

\begin{abstract}
Senna macranthera is a forest species native to Brazil that has a large natural occurrence. Its propagation occurs by seeds, which present tegumentary dormancy and need treatment for multiplication. The aim of this work was to evaluate the effect of mechanical scarification with sandpaper on $S$. macranthera seeds. Four times of mechanical scarification (0, 1, 2 and 4 seconds) and two type of soaking (without imbibition and imbibition for 24 hours) were tested, in a completely randomized design, with four repetitions. The scarification time of 1 second, without imbibition,
\end{abstract}


presented the best results for the variables of vigor and seed germination. The results showed that: mechanical scarification of $S$. macranthera seeds with sandpaper 80 in a rotating cylinder for 1 second, without imbibition, is recommended for overcoming tegumentary dormancy; the imbibition of $S$. macranthera seeds for 24 hours does not contribute to overcoming integumentary dormancy.

KEYWORDS: dormancy, rotary cylinder, germination.

\section{INTRODUÇÃO}

Senna macranthera é uma espécie arbórea da família Fabaceae e nativa da flora brasileira, com distribuição em várias regiões do país. A espécie se propaga por meio de sementes e sua madeira, apesar da baixa durabilidade, possui boa aceitação no mercado para a fabricação de caixotes, brinquedos e fins energético. Pode ser utilizada em projetos paisagísticos devido à sua beleza ornamental, além de servir como alternativa para a recuperação de áreas degradadas devido ao seu comportamento como espécie pioneira (LORENZI, 2000).

Muitas espécies da família Fabaceae apresentam como características a dormência tegumentar de suas sementes. A dormência é um mecanismo que as sementes utilizam para garantir a sua propagação, quando encontram no ambiente condições adversas para a germinação. No caso da dormência tegumentar, muitas espécies apresentam a casca dura, o que impede a absorção de água e, consequentemente, retarda ou evita a germinação (OLIVEIRA, 2012). É o caso das sementes de $S$. macranthera, que apresentam este mecanismo morfológico e necessitam de técnicas que favoreçam a entrada de água para que ocorra a germinação num menor espaço de tempo.

A superação da dormência de sementes de $S$. macranthera é recomendada em diferentes trabalhos envolvendo técnicas com o uso de ácido sulfúrico (MELO et al., 2010), fito-hormônios sintéticos (PIVETTA et al., 2018), escarificação manual com lixa (LEMOS FILHO et al., 1996) e pique manual (SANTAREM; ÁQÜILA, 1995). Entretanto, a maior parte destas recomendações apresentam problemas quanto à unificação metodológica para laboratório e viveiro, devido aos riscos e onerosidade. Além disso, a falta de padronização da técnica de superação de dormência pode resultar em percentuais de germinação diferentes daqueles obtidos em boletim de análise. Neste sentido, o uso do cilindro rotativo teria a vantagem de utilização para as duas situações.

A escarificação mecânica de sementes com o uso de lixa adaptada em cilindro rotativo mostrou ser uma prática bem sucedida para a superação da dormência imposta pelo tegumento. Espécies como Schinus molle L. (LEAL, 2015), Schinus terebinthifolia Raddi (SALDANHA et al., 2017), Lithreae molleoides (Vell.) Engl. (MISSIO et al., 2018), Senna multijuga (Rich.) H.S. Irwin \& Barneby (MISSIO et al., 2019) e Apuleia leiocarpa Vogel Macbride (MISSIO et al., 2020) apresentaram resultados satisfatórios de germinação e com baixo dano mecânico às sementes.

Neste sentido, este trabalho teve como objetivo avaliar o efeito da escarificação mecânica com lixa em sementes de Senna macranthera.

\section{MATERIAL E MÉTODOS}

O experimento foi desenvolvido no Laboratório de Análise de Sementes Florestais (LASF) do Centro de Pesquisa em Florestas, Santa Maria/RS. Sementes de $S$. macranthera pertencentes ao lote $n^{\circ} 36 / 19$, com pureza de $99 \%$, umidade de $9,61 \%$ e peso de mil sementes (PMS) de 49,61 gramas. Os frutos foram colhidos de quatro matrizes, no mês de agosto de 2019, na área de coleta de sementes (ACS) 
do Centro de Pesquisas em Florestas, Distrito de Boca-do-Monte, município de

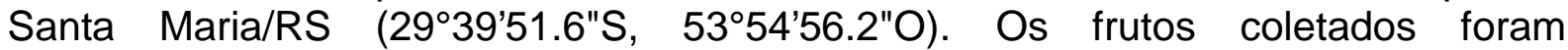
beneficiados, as sementes secas e armazenadas em câmara fria-seca com temperatura (6 a $9 \stackrel{\circ}{\circ}$ ) e umidade relativa do ar controlados (30 a 60\%).

O experimento foi conduzido em delinamento inteiramente casualizado com oito tratamentos em esquema fatorial. Foram testados quatro tempos de escarificação mecânica ( $0,1,2$ e 4 segundos) e dois tipos de embebição (sem embebição e com embebição). Para cada tratamento foram utilizadas 100 sementes, subdivididas em quatro repetições de 25 sementes, adaptando-se da metodologia de Brasil (2013).

Para fins de qualificação do melhor resultado obtido, foi realizado um segundo experimento, comparando-se com as metodologias do pique manual (tesoura) recomendada por Brasil (2013) e imersão em ácido sulfúrico concentrado por 60 minutos (MELO et al., 2010). Os tratamentos foram arranjados em delineamento inteiramente casualizado com quatro repetições de 25 sementes cada.

A escarificação mecânica foi realizada utilizando-se um equipamento elétrico do tipo cilindro rotativo $\left(\mathrm{WEG}^{\circledR}\right)$ com diâmetro de $20 \mathrm{~cm}$, quatro hastes giratórias, e rotação de 1725 rpm. Foi utilizada uma lixa de granulometria número 80, alocada no interior do cilindro, sendo subtituída após a aplicação de cada tratamento.

Para a embebição, cada tempo de escarificação das sementes em lixa foi imerso num becker contendo $50 \mathrm{~mL}$ de água destilada durante 24 horas a temperatura ambiente. Após este período, seguiu-se a metodologia descrita na sequência.

Após a aplicação de cada tratamento e contagem do dano mecânico, as sementes foram imersas em hipoclorito de sódio (2,5\%) em solução na concentração de $5 \%(\mathrm{v} / \mathrm{v})$ durante cinco minutos, para fins de assepsia, seguido da lavagem em água destilada e posterior semeadura em papel substrato do tipo Germitest $^{\circledR}$. O papel substrato de cada repetição foi umedecido com água destilada na proporção de duas vezes a sua massa. Após a inoculação das sementes, cada tratamento foi alocado num germinador do tipo Mangelsdorf com temperatura de $25 \pm 1^{\circ} \mathrm{C}$, onde permaneceu incubado durante o período de avaliações.

Foram coletadas as seguintes variáveis: Condutividade elétrica (CE) - Foi determinada utilizando-se quatro repetições de 50 sementes por tratamento. Para cada repetição foi determinada a massa das sementes e, subsequentemente, foram acondicionadas em frascos de vidro contento $75 \mathrm{~mL}$ de água deionizada, durante 24 horas em câmera do tipo B.O.D. com temperatura de $25 \pm 1 \stackrel{\circ}{ } \mathrm{C}$. Transcorrido este tempo, os frascos foram agitados durante 10 segundos e em seguida efetuada a leitura em condutivímetro Tec- 4MP $\left(\right.$ Tecnal $^{\circledR}$ ) com eletrodo de constante 1,0 . 0 resultado final foi obtido por meio da divisão da massa inicial das sementes pelo resultado da leitura de condutividade, sendo expresso em $S \mathrm{~cm}^{-1} \mathrm{~g}^{-1}$; Dano Mecânico (DM) - Determinado logo após cada tempo de escarificação das sementes. Após a retirada do tratamento do cilindro rotativo, determinou-se 0 número de sementes que sofreram dano mecânico pela exposição à lixa/hastes, com posterior retirada do tratamento antes da aplicação da assepsia e germinação. Foram consideradas sementes danificadas aquelas com danos aos cotilédones e embrião resultante de fissuras causadas pelo tempo de exposição. O resultado foi expresso em porcentagem; Índice de velocidade de germinação (IVG) Determinado através de contagens diárias da germinação durante 7 dias, Os valores obtidos foram calculados pela seguinte fórmula: IVG = G1/N1 + G2/N2 + .. Gn/Nn; onde, IVG= índice de velocidade de germinação; $\mathrm{G} 1, \mathrm{G} 2, \ldots \mathrm{Gn}=$ número de 
plântulas normais computadas na primeira contagem, na segunda contagem e na última contagem; $\mathrm{N} 1, \mathrm{~N} 2, \ldots \mathrm{Nn}$ = número de dias da semeadura à primeira, segunda e última contagem; Coeficiente de velocidade de germinação (CVG) - Calculado pela e fórmula $\mathrm{CVG}=(\mathrm{G} 1+\mathrm{G} 2+\mathrm{G} 3+\ldots+\mathrm{Gi} / \mathrm{G} 1 \mathrm{~N} 1+\mathrm{G} 2 \mathrm{~N} 2+\mathrm{G} 3 \mathrm{~N} 3+\ldots+\mathrm{GiNi}) \times 100$; onde, $\mathrm{CVG}=$ coeficiente de velocidade de germinação; $\mathrm{G}=$ número de plântulas germinadas observadas em cada dia de contagem; $\mathrm{N}=$ número de dias da semeadura a cada contagem; Tempo médio de germinação (TMG) - Calculado pela fórmula $T M G=(\mathrm{G} 1 \mathrm{~N} 1+\mathrm{G} 2 \mathrm{~N} 2+\mathrm{G} 3 \mathrm{~N} 3+\ldots+\mathrm{GiNi}) /(\mathrm{G} 1+\mathrm{G} 2+\mathrm{G} 3+\ldots+\mathrm{Gi})$, onde: $\mathrm{TMG}$ = tempo médio de germinação; $G=$ número de plântulas germinadas observadas em cada dia de contagem; $\mathrm{N}=$ número de dias da semeadura a cada contagem; Germinação (GE) - Adaptado de Brasil (2013), foi realizada com quatro subamostras de 25 sementes, com contagens realizadas aos 7 e 14 dias após a incubação, sendo as sementes germinadas posteriormente descartadas, com o resultado expresso em porcentagem. Para fins de padronização, neste trabalho foi convencionado como germinação a semente que emitiu a radícula com no mínimo 2 $\mathrm{mm}$ de comprimento; Sementes mortas (MO) - Realizada concomitantemente com a germinação, sendo que as sementes que não germinaram e apresentaram deterioração, foram classificadas como mortas. Em cada avaliação, assim como ocorreu com as sementes germinadas, aquelas consideradas mortas foram descartadas. O resultado foi expresso em porcentagem; Sementes firmes (FI) Realizada simultaneamente com a germinação, sendo que as sementes que não germinaram e não foram consideradas mortas, foram classificadas como firmes. $O$ resultado foi expresso em porcentagem.

Os dados foram submetidos à análise da variância e, posteriormente, ao teste de médias (Tukey) para variáveis que apresentaram significância a $5 \%$ de probabilidade de erro, com auxílio do software estatístico Sisvar 5.6 (FERREIRA, 2019).

\section{RESULTADOS E DISCUSSÃO}

\section{Tempos de escarificação e embebição}

As sementes de Senna macranthera submetidas a tempos crescentes de escarificação mecânica em cilindro rotativo, apresentaram uma relação direta entre o aumento do dano mecânico e a condutividade elétrica (Tabela 1).

O tempo de 1 segundo de escarificação em lixa 80 causou menores danos mecânicos quando comparado aos tempos de 2 e 4 segundos, sendo 8 pontos percentuais (p.p.) menor que o tempo de 2 segundos, e 37 p.p. inferior ao tempo de 4 segundos. Para a condutividade elétrica da solução, o tempo de 4 segundos apresentou os maiores valores, porém, significativamente igual ao tempo de 2 segundos, e estatisticamente superior ao tempo de 1 segundo. Na comparação entre os valores de condutividade elétrica, o tempo de 4 segundos resultou em 53,81 $\mathrm{S} \mathrm{cm}^{-1} \mathrm{~g}^{-1}$ a mais eletrólitos na solução que o tempo de 1 segundo.

A condutivida elétrica é um importante indicativo da qualidade fisiológica das sementes pois, ela permite, através dos eletrólitos da solução, diagnosticar em que condições estão as células embrionárias. Sementes que possuem baixo vigor, ou sofreram algum dano mecânico, tendem a apresentar valores elevados de condutividade elétrica. Isto foi constatado em outro trabalho semelhante com sementes de $A$. leiocarpa (MISSIO et al., 2020), onde tempos crescentes de escarificação das sementes com lixa 80 em cilindro rotativo, resultaram num aumento crescente da condutividade elétrica da solução. 
TABELA 1. Dano mecânico (DM) e condutividade elétrica (CE) de sementes de $S$. macranthera submetidas a quatro tempos de escarificação em lixa.

\begin{tabular}{lll}
\hline Tempo (segundos) & DM (\%) & CE $\left(\mathbf{~ S ~ c m} \mathbf{~ g}^{-1}\right)$ \\
\hline 0 (Testemunha) & $0 \mathrm{~d}^{*}$ & $23,67 \mathrm{c}$ \\
1 & $12 \mathrm{c}$ & $148 \mathrm{~b}$ \\
2 & $20 \mathrm{~b}$ & $174,81 \mathrm{ab}$ \\
4 & $49 \mathrm{a}$ & $201,81 \mathrm{a}$ \\
\hline Média & 24,20 & 145,27 \\
\hline CV (\%) & 16,39 & 8,20 \\
\hline *édias seguidas de mesma letra não diferem entre si pelo teste de Tukey a 5\% de significância.
\end{tabular}

O índice de velocidade de germinação (IVG) mostrou os maiores valores no tempo de 1 segundo de escarificação com lixa e sem embebição, sendo estatisticamente superior aos demais tratamentos (Tabela 2). Neste tempo, o IVG foi 7,81 superior à testemunha, 2,23 superior ao tempo 2 segundos, e 4,55 superior ao tempo de 4 segundos, todos sem embebição das sementes em água. $\mathrm{Na}$ comparação entre as sementes embebidas ou não, dentro de cada tempo de escarificação, apenas a testemunha não apresentou diferença estatística.

O tempo médio de germinação (TMG) e o coeficiente de velocidade de germinação (CVG) não apresentaram diferenças significativas entre os tempos de escarificação mecânica das sementes sem embebição (Tabela 2). Também não houve diferenças estatísticas entre os métodos de embebição dentro de cada tempo de escarificação.

O IVG é uma importante variável para a determinação do vigor de sementes, pois, ele se baseia no capacidade que a semente possui em germinar precocemente e, em maior número, num determinado espaço de tempo. E, neste trabalho, o tempo de 1 segundo de escarificação com lixa 80 em cilindro rotativo, mostrou-se eficiente em permitir a melhor expressão do potencial fisiológico das sementes de $S$. macranthera. Em estudos desenvolvidos por MISSIO et al. (2020) foi possível constatar o mesmo comportamento em sementes de $A$. leiocarpa submetidas à tempos de escarificação sob lixa 80 em cilindro rotativo, onde o menor tempo de escarificação, sem embebição, expressou o maior IVG. Outros estudos com sementes de Albizia pedicellaris (DC.) L. Rico (FREIRE et al., 2016) e Leucaena leucocephala (Lam.) de Wit. (MENDONÇA et al., 2020) também mostraram os maiores IVG na escarificação mecânica das sementes com lixa.

TABELA 2. Índice de velocidade de germinação (IVG), tempo médio de germinação (TMG) e coeficiente de velocidade de germinação (CVG) de sementes de $S$. macranthera sob quatro tempos de escarificação mecânica e duas formas de embebição.

\begin{tabular}{lcl}
\hline & IVG (Plântulas/dia ${ }^{-1}$ ) \\
\hline Tempo (segundos) & Sem Embebição & Com Embebição \\
\hline 0 (Testemunha) & $0,44 \mathrm{Ad}{ }^{*}$ & $0,61 \mathrm{Ac}$ \\
1 & $8,25 \mathrm{Aa}$ & $3,43 \mathrm{Ba}$ \\
2 & $6,02 \mathrm{Ab}$ & $2,17 \mathrm{Bb}$ \\
4 & $3,70 \mathrm{Ac}$ & $0,50 \mathrm{Bc}$ \\
\hline Média & 4,60 & 1,67 \\
\hline CV $(\%)$ & 13,43 \\
\hline \multicolumn{3}{c}{} \\
\hline
\end{tabular}




\begin{tabular}{lll}
\hline 0 (Testemunha) & $3,38 \mathrm{Aa}$ & $3,83 \mathrm{Aa}$ \\
1 & $2,73 \mathrm{Aa}$ & $2,61 \mathrm{Ab}$ \\
2 & $2,81 \mathrm{Aa}$ & $2,33 \mathrm{Ab}$ \\
4 & $2,71 \mathrm{Aa}$ & $2,00 \mathrm{Ab}$ \\
\hline Média & 2,91 & 2,67 \\
\hline CV (\%) & 22,10 & \\
\hline & $\mathbf{C V G}$ & \\
\hline 0 (Testemunha) & $0,32 \mathrm{Aa}$ & $0,27 \mathrm{Ab}$ \\
1 & $0,36 \mathrm{Aa}$ & $0,39 \mathrm{Aab}$ \\
2 & $0,35 \mathrm{Aa}$ & $0,42 \mathrm{Aa}$ \\
4 & $0,37 \mathrm{Aa}$ & $0,50 \mathrm{Aa}$ \\
\hline Média & 0,35 & 0,39 \\
\hline CV $(\%)$ & 17,94 & \\
\hline
\end{tabular}

*Médias seguidas de mesma letra maiúscula na linha e, minúscula na coluna, não diferem entre si pelo teste de Tukey a $5 \%$ de significância.

A porcentagem de germinação (GE) foi significativamente maior no tempo de escarificação de 1 segundo, com superioridade de 21,49 e 80 pontos percentuais (p.p.) sobre os tempos de 2, 4 e zero (testemunha) segundos, respectivamente, todos sem embebição (Tabela 3). Comparando-se os mesmos tempos com relação à embebição, os resultados mostraram que, à excessão da testemunha, os tempos de 1, 2 e 4 segundos expressaram percentuais de germinação significativamente superiores quando as sementes não foram embebidas por 24 horas logo após a escarificação. O mesmo foi constatado por Carvalho et al. (2019) em sementes de Schizolobium amazonicum Huber ex Ducke submetidas à embebição por 48 horas. Segundo estes autores, a embebição das sementes por períodos prolongados pode dificultar o suprimento de oxigênio durante o processo de germinação.

Para as sementes mortas (MO), houve uma relação direta entre o tempo de escarificação e o percentual de MO (Tabela 3). Isto provavelmente esteja relacionado ao dano mecânico, o qual além de causar as lesões visíveis (Tabela 1) também deve ter ocasionado injúrias internas às células embrionárias. A situação ficou mais complexa quando as sementes foram submetidas à embebição em água por 24 horas, resultando em percentuais de MO significativamente superiores para os tempos de 1, 2 e 4 segundos. Quanto aos percentuais de sementes firmes (FI), apenas a testemunha apresentou resultados nas duas formas de embebição.

Observando-se os resultados obtidos nas variávies de vigor (Tabela 2) e germinação (Tabela 3), percebe-se que a embebição das sementes não se apresentou como um fator positivo para o IVG e GE, pelo contrário, prejudicou a germinação em todos os tempos envolvendo a escarificação com lixa. Esta informação vai de encontro àquela obtida em trabalho semelhante com sementes $A$. leiocarpa (MISSIO et al., 2020), onde a escarificação mecânica com suscessiva embebição das sementes por 24 horas, também afetou negativamente as variáveis de vigor e germinação. Contudo, em L. molleoides foi observado o contrário, a associação entre escarificação mecânica e embebição foi positiva para a superação da dormência das sementes (MISSIO et al., 2018). Resultados satisfatórios para a germinação e emergência também foram observados em sementes de Cassia fistula L. (CRUZ et al., 2019) e Hymenaea courbaril L. (CARVALHO et al., 2020) submetidas à escarificação mecânica com lixa e posterior embebição por 24 horas. 
TABELA 3. Porcentagem de germinação (GE), mortas (MO) e firmes (FI) de sementes de $S$. macranthera sob quatro tempos de escarificação mecânica e duas formas de embebição.

\begin{tabular}{|c|c|c|}
\hline \multicolumn{3}{|c|}{ GE (\%) } \\
\hline Tempo (segundos) & Sem Embebição & Com Embebição \\
\hline 0 (Testemunha) & $6 \mathrm{Ad}^{*}$ & $9 A b c$ \\
\hline 1 & $86 \mathrm{Aa}$ & $32 \mathrm{Ba}$ \\
\hline 2 & $65 \mathrm{Ab}$ & $17 \mathrm{Bb}$ \\
\hline 4 & $37 A c$ & $4 \mathrm{BC}$ \\
\hline Média & 47 & 15 \\
\hline \multirow{2}{*}{\multicolumn{3}{|c|}{$\begin{array}{c}14,66 \\
\text { MO (\%) }\end{array}$}} \\
\hline & & \\
\hline 0 (Testemunha) & OAd & OAd \\
\hline 1 & $14 \mathrm{Bc}$ & $68 \mathrm{Ac}$ \\
\hline 2 & $35 \mathrm{Bb}$ & $83 \mathrm{Ab}$ \\
\hline 4 & $63 \mathrm{Ba}$ & $96 \mathrm{Aa}$ \\
\hline \multicolumn{3}{|l|}{ Média } \\
\hline CV (\%) & 10,17 & \\
\hline \multicolumn{3}{|c|}{$\mathrm{FI}(\%)$} \\
\hline 0 (Testemunha) & $94 A a$ & $91 \mathrm{Aa}$ \\
\hline 1 & $0 A b$ & $O A b$ \\
\hline 2 & $O A b$ & $0 A b$ \\
\hline 4 & $0 A b$ & $0 A b$ \\
\hline Média & 23 & 23 \\
\hline CV (\%) & 4,67 & \\
\hline
\end{tabular}

${ }^{*}$ Médias seguidas de mesma letra maiúscula na linha e, minúscula na coluna, não diferem entre si pelo teste de Tukey a $5 \%$ de significância.

\section{Validação da metodologia}

As informações obtidas nas tabelas 1, 2 e 3, mostraram que a escarificação mecânica em cilindro rotativo com lixa 80 por 1 segundo, sem embebição, apresentou os melhores resultados para o vigor e a germinação das sementes de $S$. macranthera. Com isso, fez-se sua comparação com outras duas metodologias descritas na literatura para fins de verificar sua eficiência (Tabela 4).

As variáveis de vigor, IVG, TMG e CVG mostraram que o tratamento com lixa 80 por 1 segundo, foi o que expressou os maiores valores sem, contudo, diferir significativamente dos tratamentos com ácido sulfúrico por 60 minutos e pique manual. Este resultado mostrou a capacidade da escarificação com lixa por 1 segundo em superar a dormência e permitir que as sementes possam germinar em maior número, com maior precocidade e num menor espaço de tempo.

A germinação (GE) das sementes de $S$. macranthera obterve os maiores percentuais na escarificação com lixa 80 em cilindro rotativo por 1 segundo, sendo este valor estatisticamente igual aos tratamentos com ácido sulfúrico por 60 minutos e pique manual. Mesmo assim, houve um ganho de 4 e 7 p.p. superior à escarifricação com ácido sulfúrico e pique, respectivamente. Como não houve percentual de sementes firmes $(\mathrm{Fl})$ para os tratamentos de superação da dormência, o percentual de sementes mortas (MO) foi a ordem inversa ao da GE, sendo o tratamento das sementes em lixa 80 por 1 segundo, aquele que resultou nos menores percentuais. No estudo com sementes de A. leiocarpa, Missio et al. (2020) também obtiveram resultados similares na comparação entre o uso de lixa 80 por 2 ENCICLOPÉDIA BIOSFERA, Centro Científico Conhecer - Jandaia-GO, v. 17 n.34; p. 6002020 
segundos em cilindro rotativo, com ácido sulfúrico e pique manual. Entretanto, sementes de $A$. leiocarpa escarificadas manualmente com lixa, mostrou-se ineficaz para superação da dormência (SOUZA; SEGATO, 2016).

TABELA 4. Índice de velocidade de germinação (IVG), tempo médio de germinação (TMG), coeficiente de velocidade de germinação (CVG), porcentagens de germinação (GE), sementes mortas (MO) e firmes ( $\mathrm{FI})$ de sementes de $S$. macranthera submetidas a três métodos de escarificação das sementes.

\begin{tabular}{|c|c|c|c|c|c|c|}
\hline Método* & IVG & TMG & CVG & $\begin{array}{l}\mathrm{GE} \\
(\%)\end{array}$ & $\begin{array}{l}\text { MO } \\
(\%)\end{array}$ & $\begin{array}{c}\mathrm{FI} \\
(\%)\end{array}$ \\
\hline Testemunha & $0,44 b^{*}$ & $3,37 a$ & $0,32 \mathrm{a}$ & $6 \mathrm{~b}$ & 0 & $94 a$ \\
\hline Lixa 80 - 1 segundo & $8,25 a$ & $2,73 a$ & $0,37 a$ & $86 a$ & 14 & $\mathrm{Ob}$ \\
\hline $\begin{array}{l}\text { Acido Sulfúrico - } 60 \\
\text { minutos }^{(1)}\end{array}$ & $7,56 a$ & $2,82 a$ & $0,35 a$ & $82 a$ & 18 & $0 \mathrm{~b}$ \\
\hline Pique manual $^{(2)}$ & $7,16 a$ & $2,83 a$ & $0,35 a$ & $79 a$ & 21 & $0 b$ \\
\hline Média & 5,85 & 2,93 & 0,34 & 63,25 & 13,25 & 23,5 \\
\hline CV (\%) & 9,36 & 19,10 & 18,19 & 6,26 & 28,57 & 4,19 \\
\hline
\end{tabular}

Os resultados obtidos neste trabalho mostram a eficiência do uso de lixa em cilindro rotativo para a superação da dormência das sementes de $S$. macranthera. $O$ tempo de 1 segundo foi suficiente para romper o tegumento, permitir a entrada de água, e desencadear o processo de germinação, sem causar danos a semente.

O cilindro rotativo pode ser vantajoso tanto para a superação da dormência de sementes em laboratório, como para a semeadura em viveiro. Pode ser considerada uma metodologia segura e ecologicamente correta, pois não utiliza reagentes químicos, e de fácil execução, quando comparada ao pique manual.

\section{CONCLUSÃO}

A escarificação mecânica de sementes de $S$. macranthera com lixa 80 em cilindro rotativo por 1 segundo, sem embebição, é recomendada para a superação da dormência tegumentar.

A embebição de sementes de $S$. macranthera por 24 horas não contribui para a superação da dormência tegumentar.

\section{REFERÊNCIAS}

BRASIL. Ministério da Agricultura e Reforma Agrária. Instruções para análise de sementes de espécies florestais. Brasília: SNDA/CGAL, 2013. 97 p.

CARVALHO, M. B. F.; ARAUjO, M. E. R. ; MENDONÇA, A. P.; CHÁVEZ, M. S.; GUTIERREZ, K. L.; RUIZ, F. J. P.; MOCHO, A. P. Métodos de superação de dormência da Schizolobium amazonicum Huber ex Ducke. Brazilian Journal of Animal and Environmental Research, v. 2, n. 1, p. 490-500, 2019. Disponível em: https://www.brazilianjournals.com/index.php/BJAER/article/view/1436. Acesso em 28 de outubro de 2020.

CARVALHO, P. R. M.; SILVA, C. A.; REIS, L. L.; MAFFUD, J. R. Superação de dormência de sementes e desenvolvimento de mudas de jatobazeiro em substratos alternativos. Colloquium Agrariae, v. 16, n. 5, p. 103-113, 2020. Disponível em: 
http://journal.unoeste.br/index.php/ca/article/view/3145/3058.

DOI:

DOI:

10.5747/ca.2020.v16.n5.a399. Acesso em 29 de outubro de 2020.

CRUZ, Y. F.; MENDONÇA, A. P.; CARVALHO, M. B. F.; SALVATIERRA, Y. V. D.; CHAVES, N. M. C.; DORADO, A. J. Métodos de superação de dormência de canafístula (Cassia fistula L.). Revista Brasileira de Ciências da Amazônia, v. 8, n. 1, p. 7-11, 2019. Disponível em: https://www.periodicos.unir.br/index.php/rolimdemoura/article/view/3682/2764.

Acesso em 27 de outubro de 2020.

FERREIRA, D. F. SISVAR: A computer analysis system to fixed effects split plot type designs. Revista Brasileira de Biometria, v. 37, n. 4, p. 529-535,. 2019. Disponível em: $\quad$ <http://www.biometria.ufla.br/index.php/BBJ/article/view/450>. $\quad$ DOI: https://doi.org/10.28951/rbb.v37i4.450. Acesso em: 10 de março de 2020. https://www.conhecer.org.br/enciclop/2018B/AGRAR/a\%20combinacao.pdf. DOI: 10.18677/EnciBio_2018B2. Acesso em 29 de setembro de 2020.

FREIRE, J. M.; ATAÍDE, D. H. S.; ROUWS, J. R. C. Superação de Dormência de Sementes de Albizia pedicellaris (DC.) L. Rico. Floresta Ambiente, v. 23, n. 2, p. 251-257, 2016. Disponível em: https://www.scielo.br/scielo.php?pid=S217980872016000200251\&script=sci_arttext\&tlng=pt. DOI: https://doi.org/10.1590/21798087.104514. Acesso em 28 de outubro de 2020.

LEAL, C. M. Superação de dormência e produção de mudas de anacauíta Schinus molle L. 2015. 90 f. Dissertação. (Mestrado em Ciência e Tecnologia de Sementes) - Universidade Federal de Pelotas, Pelotas. 2015. Disponível em: http://guaiaca.ufpel.edu.br/handle/prefix/4060. Acesso em 29 de outubro de 2020.

LEMOS FILHO, J. P. DE; GUERRA, S. T. M.; LOVATO, M. B.; SCOTTI, M. R. M. M. Germinação de sementes de senna macr.4nthera, Senna multijuga e Stryphnodendronpol polyphyllum. Pesquisa Agropecuária Brasileira, v. 32, n. 4, p. 357-361, $1997 . \quad$ Disponível em: https://seer.sct.embrapa.br/index.php/pab/article/view/4653/7234. Acesso em 27 de outubro de 2020.

LORENZI, H. Árvores brasileiras: manual de identificação e cultivo de plantas arbóreas nativas do Brasil. 5. ed. Nova Odessa: Instituto Plantarum, 2008. 368 p.

MELO, R. B.; MISSIO, E. L.; TREVISAN, R.; TRENTO, R. C. S.; MAGNAGO, F. Escarificação ácida na superação da dormência em sementes de Senna macranthera - Fabaceae. In: 25a Jornada Acadêmica Integrada, 2010, Santa Maria. Anais... Santa Maria: UFSM, 2010.

Disponível em: Anais 25 $\quad$ a https://portal.ufsm.br/jai2010/anais/trabalhos/trabalho_1041268851.htm. Acesso em 14 de outubro de 2020.

MENDONÇA, A. J. T.; SILVA, M. C. C.; BERTO, F. H. R.; GORDIM, A. R. O.; MEDEIROS, M. N. V.; LINS, W. L. Superação de dormência em sementes de Leucaena leucocephala, Lam., de Wit. com métodos físicos e químicos. Revista Verde, v. 15, n. 3, p. 325-329, 2020. Disponível em: 
https://dialnet.unirioja.es/servlet/articulo?codigo $=7560081$.

DOI:

10.18378/rvads.v15i3.7754. Acesso em 29 de outubro de 2020.

MISSIO, E. L.; SALDANHA, C. W.; MALDANER, J.; STEFFEN, J. P. K.; MORAIS, R. M. De. A combinação entre a escarificação mecânica e térmica é eficiente para a superação da dormência das sementes de Lithraea molleoides. Enciclopédia Biosfera, v. $15 . \quad$ n. 28 , p. 11-21, 2018. Disponível em: https://www.conhecer.org.br/enciclop/2018B/AGRAR/a\%20combinacao.pdf. DOI: 10.18677/EnciBio_2018B2. Acesso em 20 de outubro de 2020.

MISSIO, E. L.; SALDANHA, C. W.; MORAIS, R. M. de; STEFFEN, G. P. K.; MALDANER, J. Superação da dormência de sementes de Senna multijuga (Rich.) H. S. Irwin \& Barneby com o uso de lixa em cilindro rotativo. Enciclopédia Biosfera, v. 16. n. 30, p. 593-602, 2019. Disponível em: http://www.conhecer.org.br/enciclop/2019b/superacao.pdf.

10.18677/EnciBio_2019B54. Acesso em 20 de outubro de 2020.

OLIVEIRA, O.S. Tecnologia de sementes florestais. Curitiba: UFPR, 2012. 404p.

PIVETA, G.; MIETH, A. T.; GARCIA, F. A. O.; MUNIZ, M. F. B. Qualidade sanitária e fisiológica de Senna macranthera (DC. ex Collad.) H.S.Irwin \& Barneby quando submetida a métodos de superação da dormência. Ciência Florestal, v. 28, n. 2, p.

$\begin{array}{lcc}836-844, & 2018 . & \text { Disponível } \\ \text { https://www.scielo.br/scielo.php?script=sci_abstract\&pid=S1980- }\end{array}$

$50982018000200836 \&$ Ing =en\&nrm=iso\&tlng=pt.

em:

http://dx.doi.org/10.5902/1980509832104. Acesso em 27 de outubro de 2020.

SALDANHA, C. W.; MORO, T. S.; MISSIO, E. L; MALDANER, J.; STEFFEN, J. P. K. Escarificação mecânica e química na germinação de sementes de Schinus terebinthifolius Raddi. Enciclopédia Biosfera, v. 14, n 25, p. 519-529, 2017. Disponível em: http://www.conhecer.org.br/enciclop/2017a/agrar/escarificacao\%20mecanica.pdf. DOI: 10.18677/EnciBio_2017A47. Acesso em 27 de outubro de 2020.

SANTAREM, E. R.; ÁQUILA, M. E. A. Influência de métodos de superação de dormência e do armazenamento na germinação de sementes de Senna macranthera (Colladon) Irwin \& Barneby (Leguminosae). Revista Brasileira de Sementes, v. 17, n. 2, p. 205-209, $1995 . \quad$ Disponível em: https://lume.ufrgs.br/bitstream/handle/10183/23261/000221278.pdf?sequence=1\&isA llowed $=\mathrm{y}$. Acesso em 27 de outubro de 2020.

SOUZA, V. M. S.; SEGATO, S. V. Superação de dormência em sementes de jatobá (Hymenaea Courbaril L.). Nucleus, v.13, n.1, p. 71-80, 2016. Disponivel em:

https://core.ac.uk/download/pdf/268033583.pdf. $\quad$ DOI: $\quad$ 10.3738/1982.2278.1616. Acesso em 20 de agosto de 2020. 